
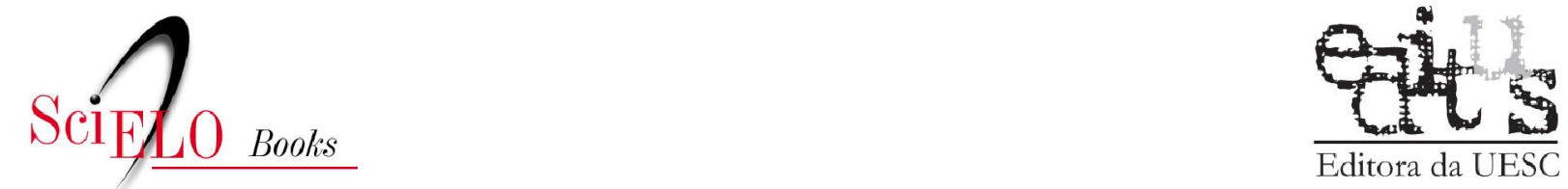

\title{
Teoria e métodos em representações sociais
}

\author{
Luci Mara Bertoni \\ Ana Lúcia Galinkin
}

BERTONI, L. M., and GALINKIN, A. L. Teoria e métodos em representações sociais. In: MORORÓ, L. P., COUTO, M. E. S., and ASSIS, R. A. M., orgs. Notas teórico-metodológicas de pesquisas em educação: concepções e trajetórias [online]. Ilhéus, BA: EDITUS, 2017, pp. 101-122. ISBN: 978-857455-493-8. Available from: doi: 10.7476/9788574554938.005. Also available in ePUB from: http://books.scielo.org/id/yjxdq/epub/mororo-9788574554938.epub.

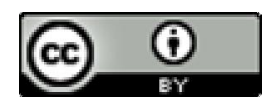

All the contents of this work, except where otherwise noted, is licensed under a Creative Commons Attribution $\underline{4.0 \text { International license. }}$

Todo o conteúdo deste trabalho, exceto quando houver ressalva, é publicado sob a licença Creative Commons Atribição 4.0.

Todo el contenido de esta obra, excepto donde se indique lo contrario, está bajo licencia de la licencia Creative Commons Reconocimento 4.0. 


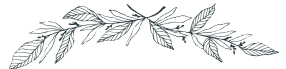 \\ TEORIA E MÉTODOS EM REPRESENTAÇÓES SOCIAIS
}

\author{
Luci Mara Bertoni ${ }^{1}$ \\ Ana Lúcia Galinkin²
}

\begin{abstract}
A Teoria das Representaçóes Sociais (TRS) tem como principal teórico o psicólogo social Serge Moscovici. Em sua obra seminal, recentemente traduzida para a língua portuguesa, o autor define representaçôes sociais (RS) como "uma modalidade de conhecimento particular tendo a função de elaboração dos comportamentos e da comunicação entre os indivíduos" (MOSCOVICI, 2012, p. 27). Assim, a TRS está centrada no funcionamento do pensamento cotidiano, com raízes tanto na sociologia e antropologia (Durkheim e Lévy-Bruhl) quanto na psicologia construtivista, socio-histórica e cultural (Piaget e Vygotsky), implicando num entrelaçamento entre o social e o individual, como afirmam Almeida e Santos (2011). Ainda de acordo com as autoras,
\end{abstract}

Para dar conta do conhecimento cotidiano, Moscovici (1989) retoma e ressignifica o conceito de representaçóes, tentando, ao mesmo tempo, colocar em evidência a especificidade da psicologia social, na medida em que, com esse conceito, ele a situará na intersecção do individual e do social (ALMEIDA e SANTOS, 2011, p. 290).

1 Professora na Universidade Estadual do Sudoeste da Bahia - UESB.

E-mail: profaluci@gmail.com

2 Pesquisadora Associada no Programa de Pós-graduação em Psicologia Social, do Trabalho e das Organizações da Universidade de Brasília -UnB.

E-mail: anagalinkin@gmail.com 
Moscovici (2005) propóe, com seus estudos, que as representaçôes que habitam a esfera do senso comum podem ser analisadas como ciência, pois tudo o que percebemos do mundo são respostas a estímulos do ambiente no qual vivemos.

O que nos distingue é a necessidade de avaliar seres e objetos corretamente, de compreender a realidade completamente; e o que distingue o meio ambiente é sua autonomia, sua independência com respeito a nós, ou mesmo, poder-se-ia dizer, sua indiferença com respeito a nós e as nossas necessidades e desejos (MOSCOVICI, 2005, p. 30).

Sendo assim, para o autor, as RS são modalidades de conhecimento que circulam em nosso cotidiano. Por meio da interação com os outros, temos a necessidade de nomear e tornar concreto o que ainda não se tornou familiar.

Segundo Moscovici, as Representaçôes Sociais são modalidades de conhecimento particular que circulam no dia-a-dia e que têm como função a comunicação entre indivíduos, criando informaçóes e nos familiarizando com o estranho de acordo com categorias de nossa cultura, por meio da ancoragem e da objetivação. Ancoragem é o processo de assimilação de novas informaçôes a um conteúdo cognitivo-emocional pré-existente, e objetivação é a transformação de um conceito abstrato em algo tangível (SAWAIA, 2004, p. 76).

Uma das funçóes das RS é "convencionalizar" os objetos, pessoas ou acontecimentos que encontram; elas lhes dão forma e localizam em uma determinada categoria, e gradualmente colocam como modelo de um determinado grupo de pessoas. Portanto, estamos todos envoltos em imagens, linguagem ou cultura que são impostos por representaçóes do grupo ao qual pertencemos. Assim, afirma Moscovici (2005, p. 35), 
nenhuma mente está livre dos efeitos de condicionamentos anteriores que lhe são impostos por suas representaçôes, linguagem ou cultura. Nós pensamos através de uma linguagem, nós organizamos nossos pensamentos, de acordo com um sistema que está condicionado, tanto por nossas representaçôes, como por nossa cultura. Nós vemos apenas o que as convençóes subjacentes nos permitem ver e nós permanecemos inconscientes dessas convençôes.

Partindo da assertiva de que "a realidade é, para a pessoa, em grande parte, determinada por aquilo que é socialmente aceito como realidade" (LEWIN apud MOSCOVICI, 2005, p. 36), Moscovici adverte que as RS não são criadas por um indivíduo isoladamente e, como consequência disso, para explicar ou se compreender uma representação, é necessário começar com aquela, ou aquelas das quais ela nasceu. Para tanto, é preciso buscar, na história, em que momento esta representação torna-se "familiar" para um determinado grupo. Em outras palavras, é preciso compreender os processos de "ancoragem" e de "objetivação", tais como definidos por este autor. Em suas palavras:

Ancoragem - Esse é um processo que transforma algo estranho e perturbador, que nos intriga, em nosso sistema particular de categorias e o compara com um paradigma de uma categoria que nós pensamos ser apropriada. [...] Ancorar é, pois, classificar e dar nome a alguma coisa (MOSCOVICI, 2005, p. 61).

Sobre a objetivação, afirma que "objetivar é descobrir a qualidade icônica de uma idéia, ou ser impreciso, é reproduzir um conceito em uma imagem" (MOSCOVICI, 2005, p. 71).

Sobre os processos de objetivação e ancoragem, elaborados por Moscovici (2003 apud SANTOS, 2005), é preciso destacar que a objetivação implica três movimentos: 
- seleçáo e descontextualizaçáo: do conjunto total de informaçóes, os sujeitos retiram algumas a partir de conhecimentos anteriores, valores culturais ou religiosos, tradiçấo cultural, experiência prévia etc.;

- formação do núcleo figurativo: é a construção de um modelo figurativo, um núcleo imaginante a partir da transformação do conceito;

- naturalizaçáo dos elementos: os elementos que foram construídos passam a ser identificados como elementos da realidade do objeto.

No processo de ancoragem, o objeto novo é reajustado para que se enquadre em categoria conhecida, adquirindo características desta categoria. Com base nos pressupostos teóricos de Moscovici (2003 apud SANTOS, 2005), isso implica:

- atribuiçáo de sentido: há o enraizamento de uma representaçáo em uma rede de significados articulados e hierarquizados a partir de conhecimentos existentes. Um sentido e um nome são atribuídos ao novo objeto;

- instrumentalizaçáo do saber: possibilita um valor funcional à representaçáo, na medida em que se torna uma teoria de referência, possibilitando a tradução e compreensão do mundo social;

- enraizamento no sistema de pensamento: as novas representaçóes se inscrevem em um sistema de representaçôes preexistentes, tornam-se familiares, ao mesmo tempo em que transformam o conhecimento anterior. Assim, o sistema de pensamento preexistente ainda predomina e serve como referência para os mecanismos de classificaçáo, comparação e de categorização do novo objeto.

Moscovici (2005) afirma que as RS pertencem, exclusivamente, ao universo consensual. Por conseguinte, elas não possuem uma estrutura específica e podem ser percebidas tanto como representaçôes tanto como ciências. Seguindo essas premissas, o objetivo da ancoragem e da objetivação é tranformar o "não-familiar" em 
"familiar", ou seja, trazer as representações do senso comum e torná-las compreensíveis pela ciência, sem alterar o universo no qual se originam. Para tanto, a pesquisa em RS exige a compreensão do processo de construção do conhecimento do senso comum que na perspectiva de Moscovici pressupóe analisar os processos de objetivação e ancoragem subjacentes a essas representaçóes.

A ciência era antes baseada no senso comum e fazia o senso comum menos comum; mas agora senso comum é a ciência tornada comum. [...] Não é fácil transformar palavras não-familiares, idéias ou seres, em palavras usuais, próximas e atuais. É necessário, para dar-lhes uma feição familiar, pôr em funcionamento os dois mecanismos de pensamento [ancoragem e objetivação] baseados na memória e em conclusôes passadas (MOSCOVICI, 2005, p. 60).

Deste modo, para o autor, as RS devem ser vistas como uma maneira específica de compreender e comunicar o que nós já sabemos. Ou ainda, são maneiras de se lidar com a memória.

Ancoragem e objetivação [...]. A primeira mantém a memória em movimento e a memória é dirigida para dentro, está sempre colocando e tirando objetos, pessoas e acontecimentos, que ela classifica de acordo com um tipo e os rotula com um nome. A segunda, sendo mais ou menos direcionada para fora (para outros), tira daí conceitos e imagens para juntá-los e reproduzi-los no mundo exterior, para fazer as coisas conhecidas a partir do que já é conhecido (MOSCOVICI, 2005, p. 78).

Por isso, adverte o autor que, para estudar uma representação, é preciso descobrir o momento em que ela emerge na esfera social. Tal advertência se estende para a retomada dos métodos de observação que, segundo ele, parecem estar esquecidos por terem sido substituídos por outros, os quais ele não despreza, mas lamenta que a observação tenha sido considerada por alguns pesquisadores 
como algo que foge do rigor científico (MOSCOVICI, 2005, p. 106). Nesta questáo situa-se o mal entendido de pesquisadores com relaçấo às RS porque os modelos tradicionalmente usados para as pesquisas de campo (questionários e/ou entrevistas fechados ou semiestruturados etc.) não conseguem alcançar a riqueza de dados que podem ser coletados a partir de observaçôes (também rigorosas) sugeridas, preferencialmente, como método das RS.

Com pressupostos teóricos e metodológicos claramente difundidos no bojo da teoria, é possível romper com

\begin{abstract}
os critérios de verdade difundidos pelos cânones científicos que desconsideram as relaçóes entre o sujeito e um objeto que faz parte de seu universo pessoal e social, passando a situá-los na funcionalidade que os conhecimentos inerentes a essa realidade assumem na vida cotidiana (ALMEIDA; SANTOS, 2011, p. 293).
\end{abstract}

Com base nestas afirmaçôes, é possível inferir que o estudo de uma representaçáo pressupóe investigar o que pensam, por que pensam e como pensam os indivíduos. Para Jodelet (1991 apud ALMEIDA e SANTOS, 2011, p. 291), as representaçóes sociais podem ser entendidas como uma

forma de conhecimento corrente, dito "senso comum", caracterizado pelas seguintes propriedades: 1. socialmente elaborado e partilhado; 2 . tem uma orientação prática de organização, de domínio do meio (material, social, ideal) e de orientação das camadas e da comunicação; 3. participa do estabelecimento de uma visão da realidade comum a um dado conjunto social (grupo, classe etc) ou cultural.

Jodelet reforça as concepçôes de Moscovici, liderando uma abordagem cultural das RS. Outras abordagens, igualmente importantes, se formam em torno da TRS: a societal, liderada por Willen Doise, também conhecida como a Escola de Genebra, e a abordagem 
estrutural, também conhecida como a Escola do Midi, liderada por Jean-Claude Abric. De acordo com Galinkin et al (2012), a grande teoria conheceu vários desdobramentos, tendo cada um deles trazido um aporte particular para o desenvolvimento da TRS.

\section{Abordagem cultural}

De acordo com Almeida (2005), não resta dúvida de que Denise Jodelet é a grande responsável por manter atual a proposição original de Moscovici, sistematizando e divulgando a teoria. Para Jodelet (2000 apud ALMEIDA, 2005, p. 128), as representaçóes sáo o estudo dos processos pelos quais os indivíduos constroem e interpretam seu mundo e sua vida, permitindo a integração das dimensôes sociais e culturais com a história.

Jodelet (1989) destaca a vitalidade, a transversalidade e a complexidade como três particularidades da RS. A autora apresenta as dificuldades iniciais de Moscovici ao mostrar os limites de pensamentos que centravam as discussóes ora no sujeito ora no social, e traz a nova perspectiva de interseção entre ambos para se compreender as relaçóes e as representaçóes sociais que se constroem a partir desta interação. Também afirma que

uma das razóes pelas quais Moscovici (1969; 1984) foi levado a renovar o uso da noçáo foi a insuficiência dos conceitos da psicologia social, a limitação de seus objetos e paradigmas. Esta perspectiva crítica ocasionou certa fluidez conceitual que foi, também, a razão de sua fecundidade. De fato, ela autorizou empreendimentos empíricos e conceituais diversos e a articulação da concepção psicossociológica com as de outras disciplinas. Ela é também a razão da vitalidade na medida em que autoriza múltiplas interpretaçóes que são fontes de avanços teóricos. Essa germinação tem diretamente a ver com as outras características que mencionamos: a transversalidade e a complexidade (JODELET, 1989). 
Quanto à transversalidade, Jodelet salienta o interesse da noçáo de RS para as ciências humanas, que conferem ao tratamento psicossociológico da representação um estatuto transverso, uma vez que articula diversos campos de pesquisa e busca a coordenação real de seus pontos de vista. Considera esta transversalidade a contribuição mais promissora nesse domínio de estudos.

Ao mesmo tempo, a autora destaca a complexidade que implica sua definição e tratamento dos fenômenos que ela busca explicar, pois é demasiado complexo compreender o funcionamento psíquico do sujeito e o funcionamento do sistema social na medida em que estes afetam e são afetados pelas representaçôes. Ainda considera que este é um programa que está em realização, mas afirma que

as representações sociais devem ser estudadas articulando elementos afetivos, mentais e sociais e integrando, ao lado da cogniçấo, da linguagem e da comunicação, a consideração das relaçóes sociais que afetam as representaçôes e a realidade material, social e ideal sobre a qual elas intervêm (JODELET, 1989).

Jodelet destaca que é nesta perspectiva supracitada que Moscovici elaborou sua teoria.

\section{Abordagem societal}

Principal teórico desta abordagem, Willen Doise problematiza a dicotomia existente no campo da Psicologia Social que se revela na cisão entre as explicaçôes "psicológicas" e "sociológicas" e considera que a TRS "supera essa dicotomia, na medida em que seus objetos de estudo situam-se no espaço de interface do indivíduo e do coletivo, admitindo de forma integrada explicaçóes tanto em nível psicológico quanto sociológico" (PACHECO, 2011). 
Para Doise (2002, p. 67), "de forma muito geral, as representaçôes sociais podem ser definidas como princípios organizadores das relaçóes simbólicas entre indivíduos e grupos". Com o objetivo de abarcar as diversas dimensōes da relação indivíduo-coletivo, Doise (1984, 1986 apud PACHECO, 2011) apresenta seu modelo teórico para a Psicologia Social que pressupóe quatro níveis de análise: intrapessoal - a maneira como o indivíduo organiza internamente suas experiências no meio social; interpessoal - como os processos interpessoais ocorrem em determinada situaçáo, tendo como foco a dinâmica das relaçóes estabelecidas em um dado momento; intergrupal - são analisadas as diferentes inserçóes sociais do sujeito em interaçáo, considerando-se como variável independente sua posição ou status social. Parte-se do pressuposto de que, em interação, os sujeitos ou grupos se posicionam de formas distintas a partir das representaçóes partilhadas por seu grupo de pertença; societal - o que valida a ordem social estabelecida é o desenvolvimento, em cada sociedade, de suas próprias ideologias, seus próprios sistemas de crenças e representaçóes, valores e normas, mesmo que sejam expressos de maneiras diferenciadas.

Para os estudiosos da denominada Escola de Genebra (Doise, Clémence, Lorenzi-Cioldi, 1992 apud DOISE, 2002, p. 68), o estudo das representaçóes sociais recorre a três hipóteses importantes: 1) a primeira hipótese postula que os diferentes membros de uma dada população partilham certas crenças comuns a propósito de um determinado objeto social; 2) a segunda refere-se à natureza das diferenças e de tomadas de posição individuais em relação a um dado objeto de representação; 3) a terceira considera as múltiplas ancoragens das tomadas de posição nas realidades coletivas.

A terceira hipótese considera que as RS, além de exprimirem um consenso entre indivíduos, marcado por certas modulaçôes ou oposiçóes individuais, são também caracterizadas por ancoragens das tomadas de posiçấo em outras realidades simbólicas coletivas. Elas se explicitam nas hierarquias de 
valores, nas percepçôes que os indivíduos constroem das relaçôes entre grupos e categorias e nas experiências sociais que eles partilham com o outro, em função de sua pertença e posição. Nesta fase, a ênfase do estudo das RS recai sobre a ancoragem das diferenças individuais (ALMEIDA, 2009a, p. 728, grifos da autora).

\section{Abordagem estrutural}

Jean-Claude Abric e seus colaboradores desenvolveram o que chamaram de "Teoria do Núcleo Central" para entender a estrutura de uma representaçáo social. Para Abric $(1998 ; 2001)$, as representaçôes são uma organização significante e não simples reflexo da realidade. Elas funcionam como um sistema de interpretação da realidade que rege as relaçóes dos indivíduos com o seu meio físico e social e vai determinar seus comportamentos e suas práticas. São elas que orientam as açôes e as relaçôes sociais. De acordo com este autor, a representação "é um sistema de pré-codificação da realidade porque ela determina um conjunto de antecipaçóes e expectativas" (ABRIC, 1998, p. 28). Se elas têm um papel fundamental na dinâmica das relaçôes sociais e nas práticas, continua o autor, elas respondem a quatro funçóes essenciais:

- Funçáo de saber: permitem compreender e explicar a realidade. As representaçóes facilitam a comunicação social e permitem as trocas sociais, a transmissão e a difusão do saber do senso comum.

- Funçáo identitária: definem a identidade e permitem a proteçáo da especificidade dos grupos. A definição da identidade do grupo garante a imagem positiva do grupo de inserção e terá um papel importante no controle social pela coletividade nos processos de socialização.

- Funçáo de orientaçáo: guiam os comportamentos e as práticas. O processo de orientação das con- 
dutas pelas representaçôes resulta em três fatores essenciais: a representação intervém diretamente nas relaçóes sociais, produz um sistema de antecipaçôes e expectativas sobre a realidade e é prescritiva de comportamentos ou de práticas obrigatórios. Ou seja, elas definem o que é lícito, tolerável ou aceitável em um dado contexto social.

- Funçáo justificadora: permitem, a posteriori, a justificativa das tomadas de posição e dos comportamentos. "A representação tem por função preservar e justificar a diferenciação social, e ela pode estereotipar as relaçóes entre os grupos, contribuir para a discriminação ou para manutenção da distância social entre eles" (ABRIC, 1998, p. 30).

Ao afirmar que "uma representação é constituída de um conjunto de informaçóes, de crenças, de opinióes e de atitudes a propósito de um dado objeto social”, Abric postula que toda representaçáo está organizada em torno de um núcleo central que é seu elemento fundamental e é ele quem determina sua significação e sua organização. Assim, o núcleo central assume duas funçôes essenciais:

- uma função generadora: ela é o elemento através do qual se cria, ou se transforma, o significado dos outros elementos constitutivos da representação. É através dele que os outros elementos ganham um sentido, um valor.

- uma função organizadora: é o núcleo central que determina a natureza dos elos, unindo entre si os elementos da representação. Neste sentido, o núcleo é o elemento unificador e estabilizador da representação (ABRIC, 1998, p. 31).

Em torno do núcleo central organizam-se os elementos periféricos que são seus componentes mais acessíveis, mais vivos e mais concretos. Eles respondem a três funções primordiais: concretização, regulação e defesa. Os elementos periféricos, ao mesmo 
tempo, tornam imediatamente compreensíveis e transmissíveis a formulação da representação em termos concretos (concretização). Constituem seu aspecto móvel e evolutivo (regulação) e onde poderão aparecer e ser toleradas as contradiçóes (defesa), uma vez que o núcleo central é resistente à mudança, posto que sua transformação provocaria uma completa alteração (ABRIC, 1998, p. 32).

Ainda com relação à importância dos elementos periféricos, Flament (1994 apud ABRIC, 1998; 2001) os considera como esquemas que são prescritores de comportamentos, permitem uma modulação personalizada das representaçôes e das condutas a elas associadas e agem na defesa quando uma representação, ou seu núcleo central, é maciçamente ameaçada. Em suas considerações sobre o trabalho de Flament, Abric (1998, p. 33, grifos do autor) destaca:

Moliner verificou um ponto fundamental da teoria de Flament, o qual esclarece os papéis específicos do núcleo central e dos elementos periféricos no funcionamento da representação: "Os esquemas centrais (o núcleo central) são normativos no sentido que eles expressam a normalidade, mas não a certitude, enquanto que os elementos periféricos condicionais, expressam o freqüente, às vezes o excepcional, mas nunca o anormal" (MOLINER, 1992, p. 328, grifos do autor).

A estrutura defendida por Abric $(1998 ; 2001)$ aponta que as representações e seus componentes (núcleo central e elementos periféricos) funcionam com seu papel específico e complementar regidos por um duplo sistema: um sistema central cuja determinação é essencialmente social e define a homogeneidade do grupo, e um sistema periférico cuja determinação é mais individualizada e contextualizada, sendo este mais flexível que o núcleo central, permitindo certa heterogeneidade de comportamentos e de conteúdos. 
É a existência deste duplo sistema que permite compreender uma das características básicas das representações, que pode parecer contraditória: elas são, simultaneamente, estáveis e móveis, rígidas e flexíveis. Estáveis e rígidas posto que determinadas por um núcleo central profundamente ancorado no sistema de valores partilhado pelos membros do grupo; móveis e flexíveis, posto que alimentando-se das experiências individuais, elas integram os dados do vivido e da situação específica, integram a evolução das relaçóes e das práticas sociais nas quais se inserem os indivíduos ou os grupos (ABRIC, 1998, p. 34, grifos do autor).

Utilizando-se da noção de "reversibilidade da situação", presente nos estudos de Flament, Abric afirma que, nos casos em que a situação é percebida como reversível, as novas práticas contraditórias desencadearão modificações na representação, integrando elementos novos e transformando os elementos periféricos. Para o autor, "o núcleo central da representação permanece estável e insensível às modificaçóes. Trata-se, pois, de uma transformação real, mas superficial da representação" (ABRIC, 1998, p. 35).

No caso das situaçóes percebidas como irreversíveis, as práticas novas e contraditórias terão consequências mais importantes na transformação da representação. Abric $(1998 ; 2001)$ nos mostra três possíveis tipos de transformação: 1) transformação "resistente": os elementos "estranhos" aparecem somente nos elementos periféricos e, por um certo tempo, são gerenciados pelos mecanismos clássicos de defesa. A multiplicação destes elementos acaba por induzir a transformação do núcleo central e, consequentemente, da representação em seu conjunto; 2) transformaçáo progressiva da representação: quando a transformação se efetiva sem ruptura e as novas práticas, progressivamente, se integram aos esquemas do núcleo central e se fundem em um novo núcleo e uma nova representação; 3) transformação brutal: quando as práticas atacam diretamente o significado central da representação e não permitem o uso dos mecanismos defensivos do sistema periférico. 


\section{Aspectos metodológicos em RS}

As representações que circundam o conhecimento elaborado e difundido entre os sujeitos sociais, suas práticas e suas "teorias" se configuram como objeto da TRS. A partir dos conceitos fundamentais de objetivação e de ancoragem, elaborados por Moscovici, é que este conhecimento do senso comum pode ser identificado e apreendido nas diversas relaçôes sociais. Para tanto, os instrumentos metodológicos eleitos para estudar determinados fenômenos podem ser adequados mediante a escolha da abordagem que melhor se adequar ao estudo específico.

Conforme destacamos anteriormente, as abordagens lideradas por Jodelet, Doise e Abric sáo complementares aos pressupostos teóricos de Moscovici. Embora cada um apresente a sua maneira de trabalhar com a TRS, todos destacam a importância de seu estudo, principalmente na busca de compreensão da interaçáo do sujeito com seu meio social, e como as RS sáo criadas a partir desta interaçáo e influenciam na mudança ou permanência dos comportamentos, ao mesmo tempo em que estes últimos afetam a criaçáo de novas representaçóes.

É importante considerar os comentários de Castro (2011, p. 6) quando nos lembra que "a topografia de cotidiano de Moscovici vai do microcosmo ao macrocosmo e seus limites são estabelecidos nas fronteiras da interaçáo social". O autor ainda comenta que

Esta espécie de topografia dinâmica supera o dualismo tradicional, introduzindo, pela natureza do objeto, um lugar de reuniáo e encontro entre distintas situaçóes. O novo objeto da Psicologia Social é um encontro, muitas vezes indiferenciado, entre indivíduo e sociedade (CASTRO, 2011, p. 6).

A diversidade de desdobramentos teóricos e a própria característica do objeto, em sua complexidade, criam as condiçôes para o 
uso de vários instrumentos e abordagens metodológicos ou mesmo para a criação de instrumentos, como no caso da Teoria de Núcleo Central. Um aspecto singular da TRS e seus desdobramentos é a possibilidade de se pesquisar o fenômenos das representaçóes sociais usando uma grande variedade de métodos de pesquisa. Considera Almeida (2001, p. 16) que

\begin{abstract}
efetivamente, não temos, até o momento, uma única técnica que permita elucidar, ao mesmo tempo, todas as informaçóes que envolvem o objeto de uma representação. Por esta razáo, muitas vezes, sua metodologia de estudo tem sido considerada frouxa, quando efetivamente o que ocorre é que ela se abre para todas as possibilidades necessárias para compreender e explicitar o fenômeno investigado.
\end{abstract}

É isto que leva à escolha de variados métodos de pesquisa utilizados por pesquisadores que adotam a TRS em suas investigaçóes científicas.

Em seu trabalho sobre as representaçôes sociais em relação à Psicanálise, realizado na década de 1960, Moscovici se valeu da interpretaçáo de textos escritos nos meios de comunicaçáo para entender como a Psicanálise, um saber reificado ou científico, foi interpretada por aqueles veículos de comunicação e reinterpretada pelo senso comum tornando-se uma representaçáo social.

Denise Jodelet, discípula de Moscovici, desenvolveu a abordagem cultural da teoria elaborada por Moscovici e utilizou, ao modo dos antropólogos e etnólogos, o método etnológico em sua investigaçáo sobre a loucura. Jodelet (2005) realizou sua pesquisa de campo em uma comunidade francesa, Ainay-le-Chateau. Tratava-se de uma pequena cidade escolhida pelo governo francês para abrigar doentes mentais como hóspedes das famílias locais, em uma nova proposta de tratamento daqueles pacientes fora dos asilos. Jodelet passou um período como habitante daquela localidade, convivendo com as famílias, 
observando o cotidiano dos habitantes e dos pacientes, participando da vida local naquilo que era possível a uma pesquisadora. Utilizou o método de observação participante, observando o dia a dia das pessoas, das famílias que abrigavam os pacientes e de seus hóspedes, realizou entrevistas. Um método que requer tempo, mas que permite uma análise em profundidade das relaçóes sociais e do comportamento das pessoas, além de suas falas (JODELET, 2005).

A abordagem estrutural das representaçóes sociais, desenvolvida por Jean Claude Abric e sua equipe da universidade de Aix-en-Provence, França, pressupóe a existência de uma estrutura nas representaçôes sociais, elaborada por um grupo, segmento social ou comunidade, e que essa estrutura tem um núcleo central que se refere aos aspectos mais fixos e permanentes de uma representação, sendo mais resistente às mudanças.

Além do núcleo central, há periferias próximas mais flexíveis mas que protegem o núcleo em relação às mudanças. E uma periferia distante do núcleo central, que pode representar o diferente, o novo ou que não é partilhado pela maioria.

Para apreender e analisar a estrutura das representaçóes sociais, o grupo de pesquisadores de Aix-en-Provence, liderado por Jean-Claude Abric, desenvolveu um instrumento de pesquisa, um questionário de evocaçáo, respondido a partir de um termo indutor escolhido pelo pesquisador, sobre o qual se pretende levantar as representaçôes construídas sobre este termo, por um determinado grupo ou segmento social. As respostas são, posteriormente, organizadas por um software, o EVOC (Ensemble de Programmes Permettant l'Analyse dês Evocations), que possibilita a realização de uma análise da evocação realizada pelos participantes da pesquisa, fornecendo dados para o reconhecimento da estrutura das representaçóes sociais.

A Análise de Evocaçáo permite identificar tanto a estrutura quanto a organização interna das representaçôes em função de dois critérios: a frequência e a ordem de evocação. É o cruzamento desses critérios que possibilita identificar a relevância dos elementos que se associam ao termo indutor. Os resultados são organizados 
em quadrantes estruturados em dois eixos. O eixo vertical corresponde à frequência de evocação das palavras, e o eixo horizontal, à ordem dessas evocaçóes. (RIBEIRO e ALMEIDA, 2003).

$\mathrm{O}$ primeiro quadrante corresponde aos elementos ou palavras e termos que são primeiramente evocados e com frequência mais elevada em relação às outras palavras ou expressóes associadas ao termo indutor. As palavras evocadas com maior frequência e prontidão pelos participantes devem, muito provavelmente, fazer parte do núcleo central das representaçóes.

$\mathrm{O}$ segundo e o terceiro quadrantes correspondem aos elementos evocados com menor frequência e mais tardiamente que aqueles do primeiro quadrante, sendo, por isto, considerados menos salientes na estrutura da representação, mas importantes e significativos em sua organização. Correspondem à periferia próxima, ou seja, aos prováveis elementos constitutivos do sistema periférico. $\mathrm{O}$ quarto e último quadrante apresenta os elementos menos frequentes, pouco evocados, correspondendo à periferia distante ou segunda periferia. Corresponde às evocaçôes mais individuais, idiossincráticas de um número limitado de sujeitos.

Como resultado da análise de evocação, pode-se realizar uma nova análise, a Análise das Palavras Principais. São considerados os elementos do núcleo central e do sistema periférico e realizada uma comparação das frequências de evocação com a frequência de palavras escolhidas pelos respondentes como as mais importantes. Este procedimento possibilita identificar outros prováveis indicadores, tanto do núcleo central quanto do sistema periférico. É possível, ainda, realizar uma Análise de Categorias, construindo categorias que simplificam os dados agrupando-os por semelhança.

Para a identificação da conexidade entre os termos, aplica-se a Técnica de Análise de Similitude aos resultados da análise prévia das evocaçóes.

A Análise de Similitude é obtida com o software SIMI. De acordo com Almeida e Cunha (2003, p.151), 
A análise de similitude das representaçôes sociais é fruto de um trabalho que vem sendo realizado desde 1962 por Flament, Degenne e Verges. Esses autores adotam os seguintes pressupostos: a) uma representação social corresponde a um conjunto de cognomes organizado por múltiplas relaçōes; b) essas relaçóes podem ser orientadas (implicação, causalidade hierarquia...), ou simétricas (equivalência, semelhança, antagonismo...), mas todas podem se "degradar" em uma relação simétrica traduzindo a ideia vaga de "ir junto” e c) essas relaçóes, em geral, são não transitivas.

Outra abordagem metodológica para os estudos de Representaçôes Sociais é introduzida por Doise, que inaugura a vertente experimental das representaçôes sociais centrada nos estudos de interação social. Segundo Almeida (2009b),

Longe de despir os sujeitos experimentais de qualquer determinação exterior à situação experimental, o procedimento que preconizamos, ao contrário, trabalha sobre as normas de comportamentos e de representaçóes que os sujeitos trazem com eles para a situaçáo experimental. Nisto, nosso procedimento difere notavelmente daqueles que visam construir situaçôes de interaçóes ditas mínimas, que não levam em consideração as relações sociais anteriormente vividas.

Doise se desvincula, assim, da pesquisa experimental tradicional da Psicologia Social, que exclui o ambiente enquanto uma variável a ser considerada, e inclui variáveis sociais em seus experimentos. Com seus colegas e alunos, em Genebra, tem desenvolvido esta nova abordagem experimental, trazendo novas perspectivas teóricas e metodológicas, não apenas para os estudos em representaçôes sociais, mas para a Psicologia Social como um todo.

Outros instrumentos de coleta e de análise de dados têm sido utilizados por diversos pesquisadores. As várias técnicas de entrevistas - não estruturadas, semiestruturadas e estruturadas, assim como os grupos focais, têm se mostrado instrumentos úteis e ade- 
quados para a investigação das representaçôes sociais em diferentes contextos. As entrevistas e os grupos focais permitem que os participantes se expressem e verbalizem seus pensamentos e sentimentos sobre os temas propostos. As diferentes formas de análise dos resultados obtidos com essas técnicas permitem aos pesquisadores apreender formas de pensamentos, explicaçóes e justificativas de comportamentos, as fontes das representaçôes, e saber se está ocorrendo mudanças nas representaçóes em função do contato com outros grupos e com a divulgação de novos conhecimentos.

Tanto as falas de entrevistados quanto as verbalizaçóes solicitadas em questionários, assim como aos respondentes do questionário de evocação podem ser analisadas pelo software ALCESTE (Analyse Lexicale par Contexte, d'um Ensemble de Segments de Texte), que realiza uma análise estatística textual e permite posterior interpretação dos resultados pelos pesquisadores.

A Análise do Conteúdo, que se refere às diversas formas de interpretação das falas dos entrevistados (BARDIN, 2011), é uma técnica que tem sido utilizada por diversos pesquisadores com diferentes abordagens teóricas, entre eles aqueles que se utilizam da Teoria das Representaçôes Sociais.

Como se pode observar, as Representaçóes Sociais têm sido estudadas partindo dos diferentes desdobramentos teóricos da proposta seminal de Moscovici, e os pesquisadores têm se valido de diversas abordagens metodológicas, não apenas pelas características do próprio objeto, como, também, pelos múltiplos olhares teóricos que o objeto permite. 


\section{Referências}

ABRIC, Jean-Claude. A abordagem estrutural das representaçóes sociais. In: MOREIRA, Antonia Silva Paredes; OLIVEIRA, Denize Cristina de. (Org.). Estudos interdisciplinares de representaçáo social. Goiânia: AB, 1998.

Prácticas sociales y representaciones. México: Coyoacán, 2001.

ALMEIDA, Angela Maria de Oliveira. A pesquisa em representaçôes sociais: fundamentos teóricos metodológicos. Ser social, n.9, jul-dez, 2001, p. 129-59.

A pesquisa em representaçóes sociais: proposiçóes teórico-metodológicas. In: SANTOS, Maria de Fátima de Souza; ALMEIDA, Leda Maria de. Diálogos com a teoria das representaçóes sociais. Pernambuco: UFPE, 2005.

Abordagem societal das representações sociais. Sociedade e Estado, v. 24, n. 3, set./dez. 2009a, p. 713-37. Disponível em <www. scielo.br >. Acesso em 26 mai. 2013.

. Os estudos experimentais sobre o desenvolvimento social da inteligência. Sociedade e Estado, v. 24, n. 3 , set./dez. 2009 b.

ALMEIDA, Angela Maria de Oliveira; CUNHA, Gleicimar Gonçalves. Representaçóes Sociais do Desenvolvimento Humano. Psicologia: Reflexão e Crítica, 16(1), p. 147-55, 2003.

ALMEIDA, Angela Maria de Oliveira; SANTOS, Maria de Fátima de Souza. A Teoria das Representaçôes Sociais. In: TORRES, Cláudio Vaz; NEIVA, Elaine Rabelo (Org.). Psicologia Social: principais temas e vertentes. Porto Alegre: Artmed, 2011.

BARDIN, Laurence. Análise de conteúdo. Ed. rev. e ampl. São Paulo: 70/Almedina, 2011. 
CASTRO, Ricardo Vieiralves de. Prefácio. In: ALMEIDA, Angela Maria de Oliveira; SANTOS, Maria de Fátima de Souza; TRINDADE, Zeidi Araújo. (Org.). Teoria das representaçóes sociais: 50 anos.Brasília: Tecknopolitik, 2011.

DOISE, Willen. Direitos do homem e força das ideias. Lisboa: Horizonte, 2002.

GALINKIN, Ana Lúcia; ALMEIDA, Angela Maria de Oliveira; ANCHIETA, Vânia Cristine Cavalcante. Representaçóes Sociais de Professores e Policiais sobre Juventude e Violência. Paidéia. set.-dez. 2012, Vol. 22, No. 53, 365-374. Disponível em <www.scielo.br>. Acesso em 10 mai. 2013.

JODELET, Denise. Représentations sociales: un domaine en expansion. In: . (Ed.). Les représentations sociales. Paris: PUF, 1989, pp. 31-61. Tradução: Tarso Bonilha Mazzotti. Revisão Técnica: Alda Judith Alves-Mazzotti. UFRJ- Faculdade de Educação, dez. 1993. Disponível em <http://portaladm.estacio.br>. Acesso em 30 mai. 2013.

2005 .

. Loucuras e representaçóes sociais. Petrópolis, RJ: Vozes,

MOSCOVICI, Serge. Representaçóes sociais: investigaçóes em psicologia social. 3.ed. Petrópolis: Vozes, 2005.

A psicanálise, sua imagem e seu público. Petrópolis: Vozes, 2012.

PACHECO, Juliana Garcia. Representaçóes sociais da loucura e práticas sociais: o desafio cotidiano da desinstitucionalização. 2011. 483f. Tese (Doutorado em Psicologia Social, do Trabalho e das Organizações) - Instituto de Psicologia, Universidade de Brasília, 2011.

SANTOS, Maria de Fátima de Souza. A teoria das representações sociais. In: SANTOS, Maria de Fátima de Souza; ALMEIDA, Leda Maria de. Diálogos com a teoria das representaçóes sociais. Pernambuco: UFPE, 2005. 
SAWAIA, Bader Burihan. Representação e ideologia - o encontro desfetichizador. In: SPINKY, Mary Jane P. (org.). O conhecimento no cotidiano: as representaçôes sociais na perspectiva da psicologia social. $3^{a}$ reimp.da $1^{a}$ ed. de 1993. São Paulo: Brasiliense, 2004. p. 73-84.

RIBEIRO, Aldry Sandro; ALMEIDA, Angela Maria de Oliveira. Violência e Masculinidade: uma breve reflexão. Cadernos JK, V. 1, N.1, p 66-68, 2002. 